\title{
Effect of Dithiothreitol on Yeast: Sphaeroplast Formation and Invertase Release
}

\author{
By A. SOMMER AND M. J. LEWIS \\ Department of Food Science and Technology, \\ University of California, \\ Davis, California 95616, U.S.A.
}

(Accepted for publication 31 July 1971)

SUMMARY

The rate of sphaeroplast formation from yeast was greater with dithiothreitol (DTT) in the reaction mixture than with 2-mercaptoethanol (2-ME) and the sphaeroplast population so produced was more rapidly and completely lysed in a non-isotonic environment. Incubation with DTT, but not $2-\mathrm{ME}$, allowed rapid formation of sphaeroplasts from yeast in stationary phase. DTT and 2-ME readily released invertase from Saccharomyces carlsbergensis, but only DTT released invertase from $S$. cerevisiae. DTT-induced release of invertase by both yeasts was dependent on DTT concentration, $\mathrm{pH}$, temperature, metal ions and yeast age, but these yeasts responded differently to oxidation and to release under suboptimal conditions.

\section{IN TRODUCTION}

Eddy \& Williamson (1957) first prepared sphaeroplasts from Saccharomyces carlsbergensis in dilute suspension by the use of snail gut juice and protracted incubation periods. Citrate, ethylenediamine tetra-acetate (EDTA) and 2-mercaptoethanol (2-ME) (Davies \& Elvin, 1964) accelerated sphaeroplast formation, but Indge (1968) found the chelating agents to be detrimental to sphaeroplast stability. Sphaeroplast formation by the use of 2-ME is slow with some yeasts, and most yeasts in the stationary phase of growth resist wall digestion, presumably as a result of their wall structure (Phaff, 1963).

Retention of invertase ( $\beta$-D-fructofuranoside fructohydrolase, EC 3.2.I.26) in the wall of Saccharomyces fragilis is partly dependent on a wall component that is reducible by $2-\mathrm{ME}$ and partly on steric hindrance of enzyme exit from the wall matrix (Kidby \& Davies, $1970 a$ ), but contrary to the view of Lampen (I968) the enzyme is not thought to be linked to the wall. A similar mechanism has been proposed by Kidby \& Davies $(1970 b$ ) for retention of invertase by $S$. cerevisiae though this enzyme has not been released by chemical reduction.

We have applied dithiothreitol (DTT), a more powerful reducing agent than 2-ME, to sphaeroplast formation and invertase release from yeast.

\section{METHODS}

Organisms. Saccharomyces cerevisiae NCYC 1005, S. fragilis NCYC 15I or 100, and $S$. carlsbergensis NCYC 5I I or University of California, Davis, 67-80 were grown in shake culture at $2 \mathrm{I}^{\circ}$ on a rich semi-defined medium containing glucose (Lewis \& Phaff, I965). The yeasts were harvested in the $\log$ phase (after $12 \mathrm{~h}$.) or stationary phase (after $36 \mathrm{~h}$.), washed in distilled water by centrifugation and used immediately. Yeast density was determined by 
weighing a dried portion of the yeast suspension, which was then diluted to a standard density for use.

Sphaeroplast formation. Saccharomyces carlsbergensis (10 $\mathrm{mg}$. dry weight $/ \mathrm{ml}$.) suspended in phosphate buffer $(0 \cdot \mathrm{I} \mathrm{M}, \mathrm{pH} 6 \cdot 7)$ made $\mathrm{I} \cdot 0 \mathrm{M}$ with mannitol and $\mathrm{IO}^{-2} \mathrm{M}$ with DTT or 2-ME, was treated with 0 " 2 vol. of 'Glusulase' (Endo Laboratories Inc., Garden City, New York, U.S.A.). For use 'Glusulase' was supplemented with $0 \cdot I$ vol. I \% (w/v) cysteine hydrochloride solution and diluted with 9 vol. distilled water. Sphaeroplast formation during incubation at $37^{\circ}$ or $30^{\circ}$ was followed by the lysis method of Indge (1968), in which was determined the $E_{660}$ of a sample (O.I ml.) of the digestion mixture diluted with distilled water $(2.9 \mathrm{ml}$.), and by direct observation in the phase-contrast microscope. Sphaeroplasts were harvested by centrifugation $(5000 \mathrm{~g})$ at $4^{\circ}$ and washed with the mannitol/phosphate buffer solution.

Invertase assay. Yeast (Io mg. dry weight $/ \mathrm{ml}$.) suspended in phosphate buffer (O.I M, $\mathrm{pH} 7.0$ ) was made $\mathrm{IO}^{-2} \mathrm{M}$ with DTT or 2-ME. After centrifuging to remove yeast the released enzyme was reacted with sucrose $(5 \%, \mathrm{w} / \mathrm{v})$ in acetate buffer $(0 \cdot 2 \mathrm{M}, \mathrm{pH} 5 \cdot 0)$ for $\mathrm{I} \cdot 0 \mathrm{~h}$., and the reducing sugar determined by a standard ferricyanide/iodometric method (American Society of Brewing Chemists, 1958). Invertase is reported as mg. reducing sugar (glucose equivalent $) / \mathrm{ml}$. yeast suspension. Invertase of intact yeast was determined in the same way but with sodium fluoride $(\mathrm{O} \cdot \mathrm{I} \mathrm{M})$ present.

DTT was measured in the presence of reducing sugar by the same ferricyanide method, but the heating procedure necessary for sugar determination was omitted.

Reagents. DTT was obtained from Sigma Chemical Company, St Louis, Missouri, U.S.A., and was $94 \%$ in the reduced form as determined by ferricyanide titration.

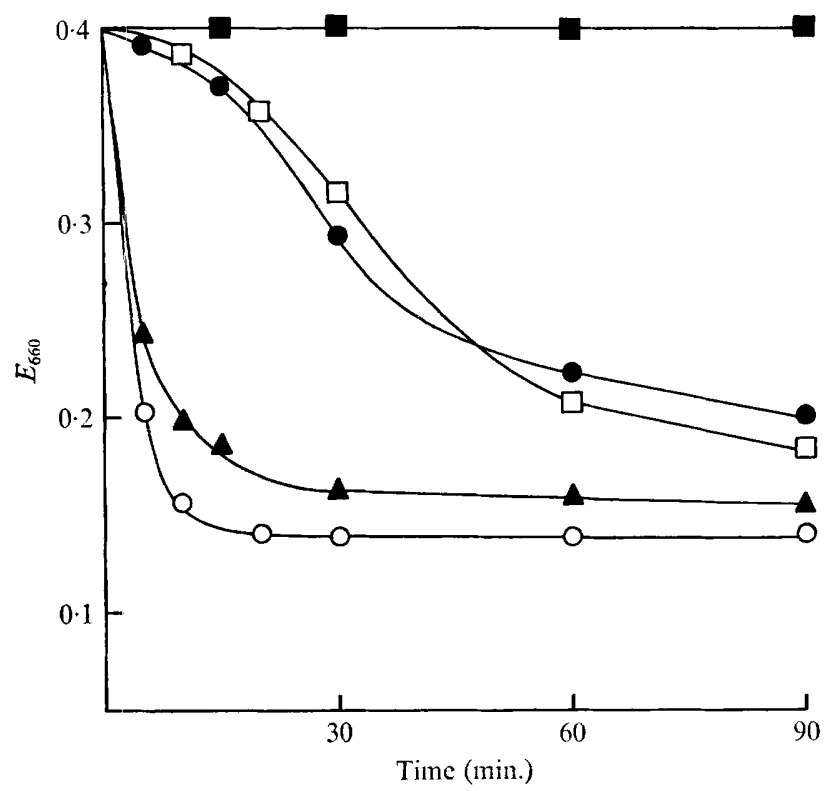

Fig. I. Formation of sphaeroplasts from Saccharomyces carlsbergensis $67-80.0$, $12 \mathrm{~h}$. yeast ?with DTT $10^{-2} \mathrm{M} ; 0,12 \mathrm{~h}$. yeast with $2-\mathrm{ME} 10^{-2} \mathrm{M} ; \square, 36 \mathrm{~h}$. yeast with DTT $10^{-2} \mathrm{M} ; \boldsymbol{\Delta}, 36 \mathrm{~h}$. yeast exposed $20 \mathrm{~h}$. to DTT $10^{-2} \mathrm{M} ; \boldsymbol{\square}, 36 \mathrm{~h}$. yeast with or without $20 \mathrm{~h}$. exposure to $2-\mathrm{ME} 10^{-2} \mathrm{M}$, and all controls. 


\section{RESULTS}

Sphaeroplast formation. Sphaeroplast formation with 2-ME in the reaction mixture was substantially slower than with DTT present under otherwise identical conditions (Fig. I). Log-phase yeast treated (20 min.) with DTT, then washed, was converted equally rapidly. Yeast taken from the stationary phase of growth was resistant to the wall-digesting enzyme in the presence of 2-ME, but was attacked when DTT was present; if treated with DTT for sufficient time such cells were rapidly converted (Fig. I, Table r). DTTtreated cells were resistant to the sphaeroplasting enzyme if treated with ferricyanide (Table I). When DTT and 2-ME were used in admixture no increase in the rate of sphaeroplast formation was achieved with log-phase or stationary-phase cells.

\section{Table I. Sphaeroplast formation from Saccharomyces carlsbergensis $67-80$ with $D T T\left(\mathrm{IO}^{-2} \mathrm{M}\right)$ in the reaction mixture}

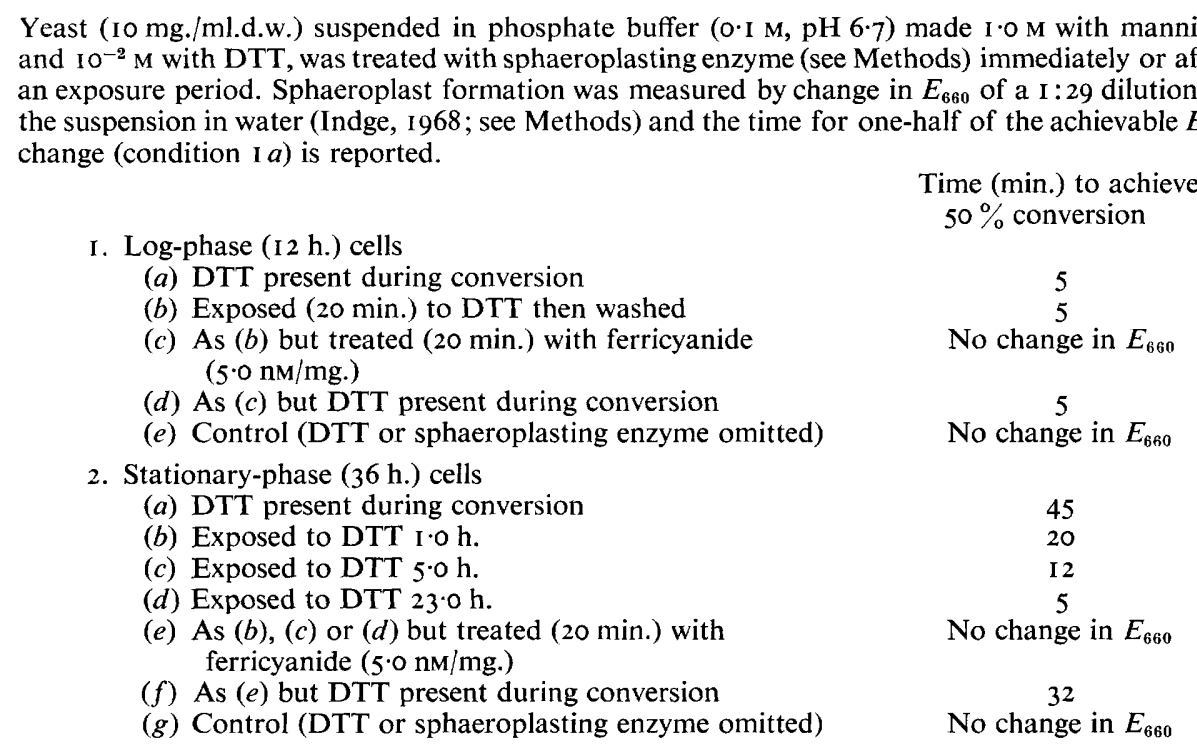

The rate of sphaeroplast formation in the presence of DTT was not markedly pHdependent in the range $\mathrm{pH} 6 \cdot 2$ to 7.0 but was greatest at $\mathrm{pH} 6.7$. It was more rapid at $37^{\circ}$ than at $30^{\circ}$, and decreased asymptotically with DTT concentration (Fig. 2). Examination of the yeast under a phase-contrast microscope indicated $100 \%$ conversion to sphaeroplasts in I 5 min. in the presence of DTT.

Even with prolonged incubation sphaeroplast formation was not as complete in the presence of 2-ME as with DTT (Fig. I). A 2-ME-sphaeroplast population was found less susceptible to lysis in non-isotonic environments than a DTT-sphaeroplast population (Fig. 3).

Release of invertase. We found Saccharomyces fragilis I00 or I5I to contain half as much invertase, measured on whole cells, as $S$. carlsbergensis 5 I I or $S$. cerevisiae 1005 , whereas the latter two yeasts contained almost equal amounts of the enzyme. Since $S$. carlsbergensis 5I I was found to have the same pattern of release with 2-ME as S. fragilis (Kidby \& Davies, I970a), S. carlsbergensis 5I I was the preferred comparison organism. 
In the presence of DTT, invertase was released linearly with time (up to $\mathrm{I} \cdot \mathrm{O}$.) from Saccharomyces carlsbergensis 5 I I under all conditions tested, the rate of release being about five times that from S. cerevisiae I005 (Fig. 4, Table 2). However, under suboptimal conditions, release of invertase from $S$. cerevisiae was biphasic (Fig. 4). For the two yeasts

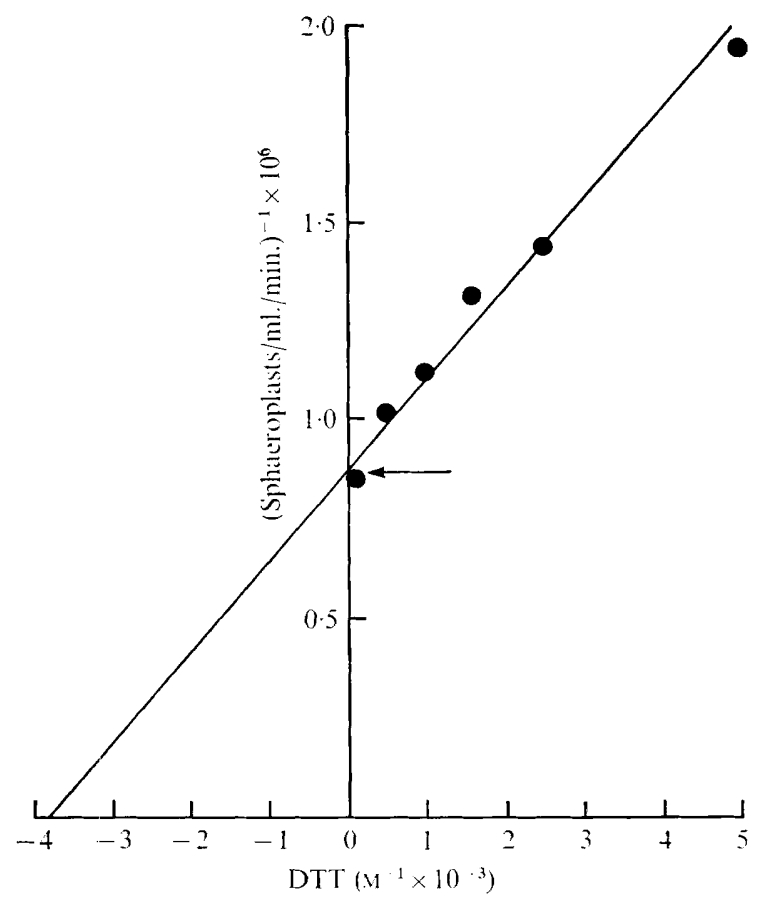

Fig. 2. Effect of DTT concentration on rate of sphaeroplast formation from Saccharomyces carlsbergensis $67-80$. Intercept indicates a $v_{\max }$ of $1 \cdot 15 \times 10^{8}$ sphaeroplasts $/ \mathrm{ml} . / \mathrm{min}$.

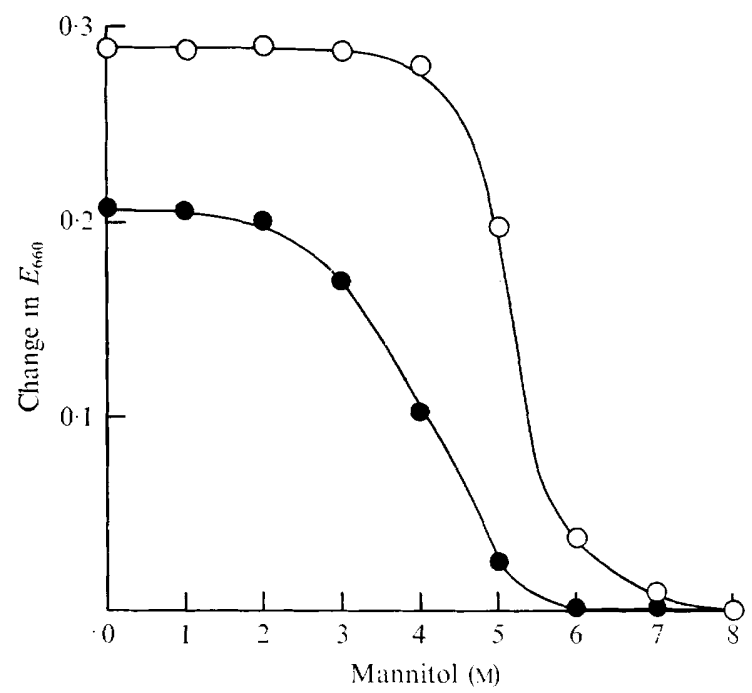

Fig. 3. Lysis, in solutions of mannitol, of a population of sphaeroplasts prepared from Saccharomyces carlsbergensis $67-80$ in the presence of DTT (O) or 2-ME (๑). 
invertase release was dependent to the same relative extent on $\mathrm{pH}$, temperature, DTT concentration, yeast age, chelating agents, and divalent metal ions (Table 2).

Release of invertase was slowed when DTT was removed by washing the yeast, a treatment that was more effective with Saccharomyces cerevisiae than with $S$. carlsbergensis, especially if the cells were vigorously shaken or oxygenated during washing (Fig. 5). This

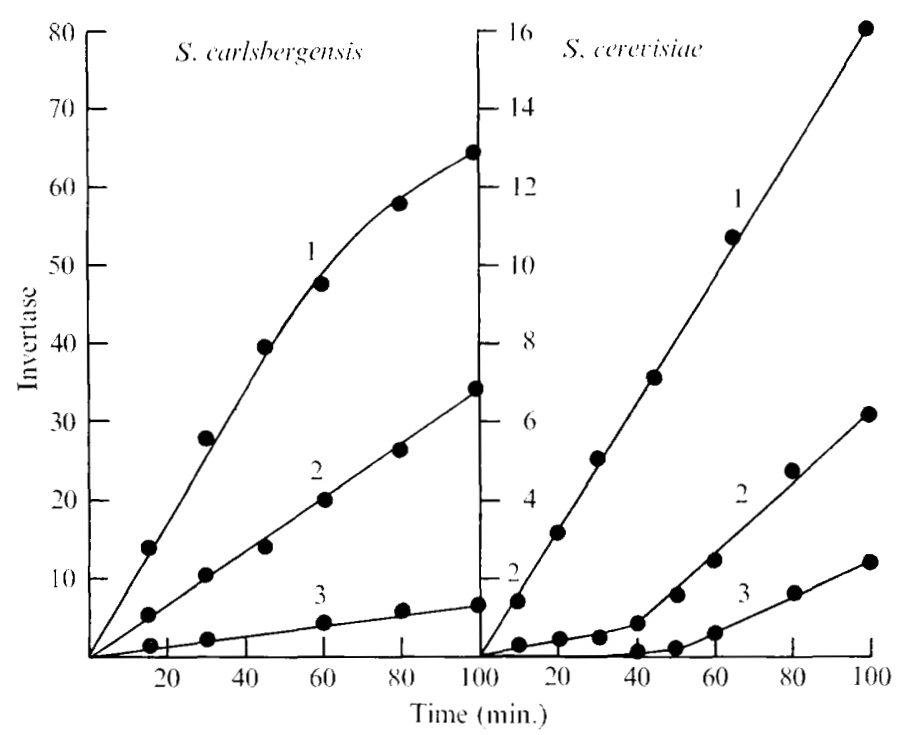

Fig. 4. Effect of DTT concentration and $\mathrm{pH}$ on release of invertase from Saccharomyces carlsbergensis and $S$. cerevisiae. Curve $1, \mathrm{pH} 7 \cdot 1,10^{-2} \mathrm{M}$-DTT; curve 2, $\mathrm{pH} 5.0,10^{-2} \mathrm{M}$-DTT; curve 3 , for Saccharomyces carlsbergensis $\mathrm{pH} 5 \cdot 0,2 \times 10^{-3} \mathrm{M}-\mathrm{DTT}$, for $S$. cerevisiae $\mathrm{pH} 5.0,5 \times 10^{-3} \mathrm{M}-\mathrm{DTT}$.

difference was confirmed when DTT was removed by oxidation with ferricyanide; a slight excess of ferricyanide $(2 \cdot 0 \mathrm{~nm} / \mathrm{ml}$.) instantly halted invertase release from $S$. cerevisiae, whereas a large excess of ferricyanide $(20 \mathrm{nM} / \mathrm{ml}$.) failed to achieve the same result with $S$. carlsbergensis (Fig. 5). The extent of reaction of these two yeasts with ferricyanide was essentially the same $(1 \cdot 25 \mathrm{~nm} / \mathrm{mg}$.), but the rate of reaction was more rapid with an excess of ferricyanide (Table 3 ). Change of $\mathrm{pH}$ (from 7.0 to $5^{\circ}$ ) was relatively ineffective in slowing invertase release from either yeast (Fig. 5).

The enzyme readily equilibrated with the intracellular water when yeast, heated in a boiling water bath $\mathrm{I} .5 \mathrm{~min}$. to inactivate invertase and to disrupt the cytoplasmic membrane, was suspended in a solution of invertase containing DTT $\left(\mathrm{IO}^{-2} \mathrm{M}\right)$ prepared from Saccharomyces carlsbergensis. This equilibration was prevented by treatment of the heated yeast with ferricyanide (Table 4). In this system there was little difference between $S$. carlsbergensis and S. cerevisiae.

\section{DISCUSSION}

The reducible components of the yeast wall are not well defined, but disulphide bridges have been ascribed a role in cell division (Nickerson, 1963) and in the structural integrity of the wall (Bacon, Milne, Taylor \& Webley, 1965). It has been generally accepted that it is by reduction of disulphide bridges that thiols are effective in sphaeroplast formation and in inducing invertase release, but the re-oxidization of such reduced links has not been dis- 
Table 2. Effect of several factors on release of invertase from Saccharomyces carlsbergensis $5 \mathrm{II}$ and $\mathrm{S}$. cerevisiae $\mathrm{I} 005$

Invertase was extracted from $\mathrm{I} 2 \mathrm{~h}$. yeast cells ( $\mathrm{r} O \mathrm{mg}$. dry $\mathrm{wt} / \mathrm{ml}$ ) ) in phosphate buffer (o. $\mathrm{I} \mathrm{M}, \mathrm{pH}$ 7.0 ) with DTT $\left(\mathrm{IO}^{-2} \mathrm{M}\right)$ for $\mathrm{I} \cdot \mathrm{O}$. at $30^{\circ}$ unless otherwise shown. Invertase is reported as reducing sugar (glucose equivalent, produced from sucrose at $\mathrm{pH} 5 \cdot \mathrm{o}$ ), $\mathrm{mg} . / \mathrm{h} . / \mathrm{ml}$. of yeast suspension.

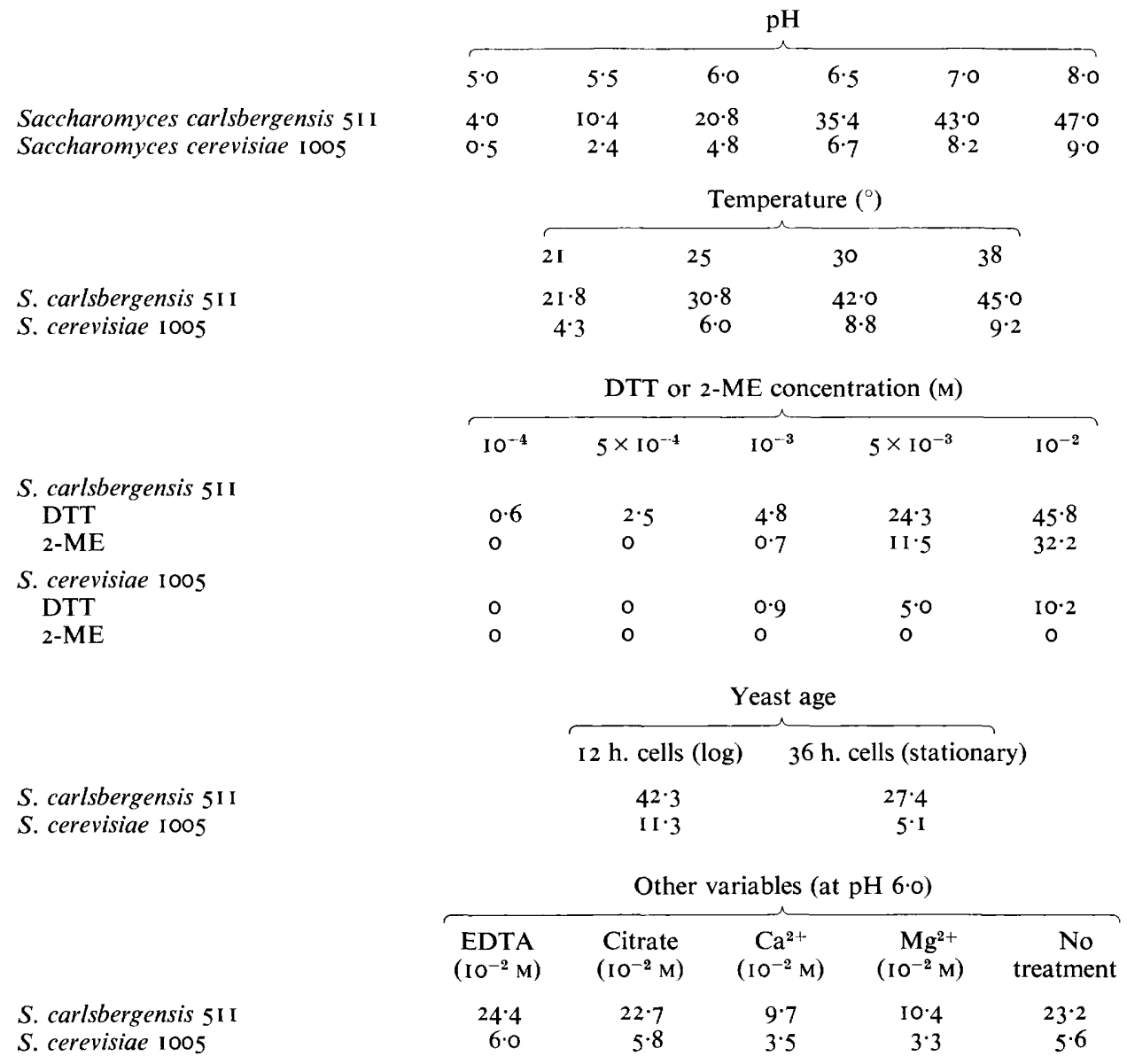

cussed. Destruction of thiol by excess ferricyanide (Kidby \& Davies, 1970 $a$ ) was effective only in the initial, thiol-dependent stage of invertase release, and the same effect was demonstrable with non-reducing treatments (e.g. pH-change). Using invertase release as a criterion, we find Saccharomyces cerevisiae much more susceptible to oxidation than $S$. carlsbergensis long after a thiol-dependent step should have been exhausted (Fig. 4). We do not attribute this to persisting thiol dependence because $\mathrm{pH}$ change was ineffective (Fig. 5), but to reoxidation of the thiol-reducible site; it is evident that the reducible site in $S$. cerevisiae or $S$. carlsbergensis differ. The notion of reoxidation is further supported by the facts that, first, there was a measurable reaction of intact yeasts with ferricyanide (Table 3), and, secondly, DTT-reduced, ferricyanide-treated cells did not form sphaeroplasts (Table I). The reducible site associated with invertase release is shown to be more stable in S. cerevisiae than in $S$. carlsbergensis by firstly the need for the more powerful reducing agent (DTT) with 


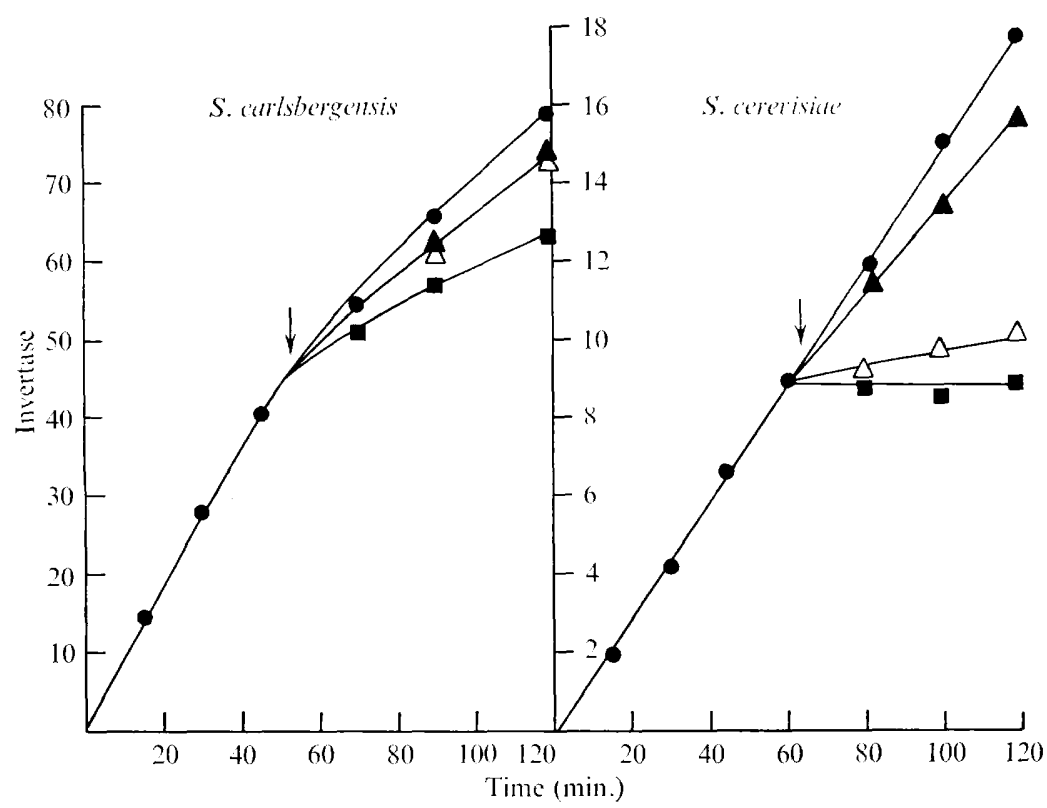

Fig. 5. Release of invertase from Saccharomyces carlsbergensis or S. cerevisiae by DTT (10 $\left.{ }^{-2} \mathrm{M}\right)$ at $\mathrm{pH} 7 \cdot \mathrm{I}$. Treatments at $\downarrow: \Theta$, no treatment; $\Delta, \mathrm{pH}$ change from $7 \cdot \mathrm{I}$ to $5 \cdot 0 ; \Delta$, cells washed with oxygenation; $\mathbf{\square}$, ferricyanide added, for $S$. carlsbergensis $20 \mathrm{nM} / \mathrm{mg}$., for $S$. cerevisiae $2 \cdot 0 \mathrm{nM} / \mathrm{mg}$.

Table 3. Reaction of Saccharomyces carlsbergensis 5I I or S. cerevisiae 1005 with ferricyanide at $30^{\circ}$

$\begin{array}{ccc}\begin{array}{c}\text { Amount of } \\ \text { ferricyanide added } \\ (\mathrm{nM} / \mathrm{mg} \text {. yeast) }\end{array} & \begin{array}{c}\text { Amount of } \\ \text { ferricyanide reduced } \\ \text { (nM/mg. yeast) }\end{array} & \begin{array}{c}\text { Rate of react } \\ \text { (nM/min./mg. }\end{array} \\ 5.0 & 1 \cdot 25 & 0.12 \\ 3.0 & 1 \cdot 25 & 0.12 \\ 2 \cdot 0 & 1 \cdot 25 & 0.09 \\ \mathrm{I} \cdot 0 & 1 \cdot 0 & 0.05 \\ 0.2 & 0.2 & 0.007\end{array}$

S. cerevisiae; secondly, the appearance of biphasic release under suboptimal conditions with $S$. cerevisiae but not $S$. carlsbergensis (Fig. 4) (this becomes evident when reduction by the thiol is a rate limiting step for release (Kidby \& Davies, 1970a)); and thirdly, inhibition of release by oxygenation in S. cerevisiae (Fig. 5). We believe the stability of the reducible site in $S$. cerevisiae explains the tenacious retention of invertase by this yeast. Other than this difference of degree, the patterns of invertase release in $S$. carlsbergensis and $S$. cerevisiae were remarkably similar (Table 2). This supports the conclusion of Kidby \& Davies (I970 $b$ ) that the mechanism of invertase retention is the same in the two yeasts.

The view of the yeast wall as a permeability barrier (Kidby \& Davies, $1970 b$ ) is directly demonstrated in Table 4. Oxidation of the yeast wall may well hinder enzyme perfusion into the reduced, heated cell, by the same mechanism as enzyme exit is hindered in the intact unreduced yeast, and supports the conclusion (Kidby \& Davies, 1970a) that invertase is entrained within, not attached to, the wall. 


\section{Table 4. Perfusion of invertase into heat-treated Saccharomyces carlsbergensis 5I I or S. cerevisiae 1005}

Yeast ( $10 \mathrm{mg} . / \mathrm{ml}$ ) was suspended $30 \mathrm{~min}$. in a solution of invertase, containing DTT ( $1 \mathrm{O}^{-2} \mathrm{M}$ ) prepared from $S$. carlsbergensis. Ferricyanide was added, as indicated, before or after enzyme addition in excess of the amount required to oxidize the DTT present. Cells were harvested by centrifugation, the tubes mopped out with tissue, and the invertase determined (as Table 2).

Treatment

(a) Heated ( $.5 \mathrm{~min} .100^{\circ}$ ) yeast (control), no invertase added

(b) Heated ( $\left.\mathrm{I} \cdot 5 \mathrm{~min} .100^{\circ}\right)$ yeast with added invertase

(c) As (b), but ferricyanide $(5.0 \mathrm{~nm} / \mathrm{mg}$.) added $20 \mathrm{~min}$. after addition of the invertase

(d) As (b), but ferricyanide $(5.0 \mathrm{~nm} / \mathrm{mg}$.) added $20 \mathrm{~min}$. before addition of the invertase
Invertase in

Invertase in packed packed cell volume cell volume after washing

$\begin{array}{cc}2 \cdot 0 & 1 \cdot 9 \\ 32 \cdot 0 & 2 \cdot 0 \\ 30 \cdot 2 & 7 \cdot 4 \\ 15 \cdot 1 & 1 \cdot 8\end{array}$

$2 \cdot 0$

$7 \cdot 4$

$\cdot 8$

Difficulty in forming sphaeroplasts from some yeasts, and from yeast in stationary phase, may be explained by the presence in the wall of stable disulphide bridges such as are described above (Phaff, 1963). The efficacy of DTT, but not 2-ME, with stationary-phase yeasts (Fig. I), and the slower release of invertase from such yeast (Table 2) are indicative of this. There is no reason to suppose that those sulphide bridges involved in sphaeroplast formation are the same in nature and location as those which control invertase release.

We recommend DTT as a reagent of choice in sphaeroplast formation because of: (i) its speed in the absence of chelating agents (Fig. I); (ii) its effectiveness in high yeast densities (analysis of the asymptote (Fig. 2) does not show saturation and suggests higher yeast densities may be used with equal efficiency); (iii) the more complete and even yeast wall removal as judged by sphaeroplast lysis (Fig. 3); (iv) its effectiveness with stationary-phase yeasts (Fig. I). The method may find particular use for the gentle isolation of labile or transitory subcellular particles from whole yeast.

We are indebted to Master Brewers Association of America for financial support of part of this work, and to Professor J. S. Hough for laboratory accommodation for M. J. L. at the University of Birmingham.

\section{REFERENCES}

American Society of Brewing Chemists (1958). Methods of Analysis, 6th edn, pp. I62-I68. Wisconsin: American Society of Brewing Chemists Publications.

Bacon, J. S. D., Milne, B. D., TAYlor, I. F. \& Webley, D. M. (I965). Features of the cell wall structure of yeast revealed by the action of enzymes from a non-fruiting Myxobacterium (Cytophaga johnsonii). Biochemical Journal 95, 28C.

Davies, R. \& Elvin, P. A. (I964). The effect of $\beta$-mercaptoethanol on release of invertase and formation of protoplasts of Saccharomyces fragilis. Biochemical Journal 93, 8P.

EdDy, A. A. \& Williamson, D. H. (1957). A method of isolating protoplasts from yeast. Nature, London I79, $1252-1253$.

INDGE, K. J. (1968). The effects of various anions and cations on the lysis of yeast protoplasts by osmotic shock. Journal of General Microbiology 5I, 425-432.

KIDBY, D. K. \& DAvIES, R. (1970a). Thiol-induced release of invertase from cell walls of Saccharomyces fragilis. Biochimica et biophysica acta 201, 26I-266. 
KidBy, D. K. \& Davies, R. (I970 b). Invertase and disulphide bridges in the yeast wall. Journal of General Microbiology 6r, 327-333.

LAMPEN, J. O. (1968). External enzymes of yeast; their nature and formation. Antonie van Leeuwenhoek 34, $\mathrm{I}-\mathrm{I} 8$.

Lewis, M. J. \& Phaff, H. J. (1965). Effect of environmental conditions on yeast. II. Shock excretion of amino acids. Journal of Bacteriology 87, I389-I 396.

NiCkERSON, W. J. (I 963). Symposium on biochemical bases of morphogenesis in fungi. IV. Molecular bases of form in yeasts. Bacteriological Reviews 27, 305-324.

Phaff, H. J. (1963). Cell wall of yeasts. Annual Review of Microbiology 17, 15-30. 